Olívia Maria Gomes da Cunha (ed.), Maroon Cosmopolitics: Personhood, Creativity and Incorporation. Leiden, the Netherlands: Brill, $2018 . \mathrm{xv}+380 \mathrm{pp}$. (Cloth US\$191.00)

Throughout the second half of the twentieth century, anthropologists have studied Maroon societies in Suriname and French Guiana, unique ethnic groups born of the violent clashes and cultural encounters that accompanied the colonization of the New World, but in the process they have produced texts with wider and more substantial impact. Through the case study of the Maroons, they have demonstrated a new way of understanding sociocultural change — not as "tainting" the ideal cultural form, but rather as an aspect of all human communities - and opened important discussions about the (dis)continuities in sociocultural developments.

Banal as these statements may sound, they are important starting points for the evaluation of Maroon Cosmopolitics, as the processes of cultural change and fabrication and reconfiguration of Maroons' identities have continued, and in fact accelerated, in past decades. The version of Maroon culture that was described in the foundational texts from the 1970s and 1980s is rapidly disappearing - or rather evolving further. In some respects, Maroon culture is losing its exoticism and "otherness," thanks to expanded knowledge of who the Maroons were and are.

There are certainly factors objectively threatening the community cohesion and the group identities of the Maroons. Since the Suriname civil war (1986-92), there has been an abrupt transition from near absolute isolation to increased visits by government officials and tourists, and a subsequent intensification of cultural exchange; a loss of territorial sovereignty; forced migrations resulting from civil wars and environmental disruption; and the impact of the globalized economy. All of these factors have led to changes in social hierarchies and interpersonal relations, the redefinition of tasks assigned to men and women, the simplification and decontextualization of many traditional practices, and more. At the same time, as Olívia Gomes da Cunha points out (p. 1), there is a danger of automatic idealization of the "original" way of living of the mid-twentieth century, of perceiving any subsequent transformation as "loss and decay."

The complexity of Maroon worldviews, composed of multilayered relationships with humans and nonhumans, both descending from the past and brought about by the configurations of postmodern sociopolitics-what Gomes da Cunha calls "a constant flux of actualization" (p. 13) — motivated her to call on the concept of "cosmopolitics" as a point of departure for the exploration of Maroon societies at the dawn of the twenty-first century. The book's 
essays address adjustments of traditional cultural patterns (rituals, language, arts and crafts, dwelling structures) as well as the role of new media and novel ways of expressing individual and collective identities, such as dance contests (in the chapter by Corinna Campbell). Some chapters focus on the still-existing clashes and competitiveness among the distinct Maroon groups; others, on the emergence of new forms of Maroon, or sometimes "pan-Maroon," identities in urban environments, and their complex relationships with nationalist movements and state policies in Suriname and French Guiana; see, for example, the excellent chapters by Diane Vernon and Clémence Léobal, describing the clashes of Maroon traditions with French legislature.

The volume, based on recent research and composed as a mosaic of case studies from various localities (traditional upriver villages as well as shanty towns on the outskirts of big cities) focusing on various aspects of Maroon culture, and applying distinct methodologies and theoretical frameworks, is nevertheless compact and comprehensive. The contributors aim to assess these processes and dilemmas through the eyes of the Maroons themselves as much as via the analytical lens of the anthropologist. The Maroons, as they are portrayed in the respective chapters, are not passive victims of globalization and cultural domination. (See specifically the discussion in the chapter by Kenneth Bilby and Rivke Jaffe on Maroon music, p. 331.)

While often presenting more general conclusions beyond the specific group studies, none of the authors promote the illusion of a unified "Maroon culture," nor aspire to formulate universal proposals for the solution of the "Maroon problem" in Suriname or French Guiana. But just like the pioneer texts on the Maroons published half a century ago, they bring forward important intellectual issues not only with respect to the specific situation of the peoples studied, but also the more general questions and problems addressed at present by anthropologists worldwide. They challenge established notions of "authenticity" and the stereotypes of unidirectional cultural transfers from "cores" toward "peripheries," and they provoke a redefinition of the notion of "creolization" in new contexts and situations.

\section{Markéta Kř̌žová}

Center of Ibero-American Studies, Faculty of Arts, Charles University, Prague marketa.krizova@ff.cuni.cz 